\title{
Hypoxia-inducible factor 1 alpha in high-risk breast cancer: an independent prognostic parameter?
}

\author{
Günther Gruber ${ }^{1}$, Richard H Greiner ${ }^{1}$, Ruslan Hlushchuk ${ }^{2}$, Daniel M Aebersold ${ }^{1}$, \\ Hans J Altermatt ${ }^{3}$, Gilles Berclaz ${ }^{4}$ and Valentin Djonov ${ }^{2}$
}

${ }^{1}$ Department of Radiation Oncology, University of Bern, Switzerland

${ }^{2}$ Institute of Anatomy, University of Bern, Switzerland

${ }^{3}$ Pathology Laenggasse, University of Bern, Switzerland

${ }^{4}$ Department of Gynaecology, University of Bern, Switzerland

Corresponding author: Valentin Djonov (e-mail: djonov@ana.unibe.ch)

Received: 31 Jul 2003 Revisions requested: 21 Oct 2003 Revisions received: 9 Feb 2004 Accepted: 16 Feb 2004 Published: 9 Mar 2004

Breast Cancer Res 2004, 6:R191-R198 (DOI 10.1186/bcr775)

(c) 2004 Gruber et al., licensee BioMed Central Ltd. This is an Open Access article: verbatim copying and redistribution of this article are permitted in all media for any purpose, provided this notice is preserved along with the article's original URL.

\begin{abstract}
Background: Hypoxia-inducible factor 1 alpha (hif- $1 \alpha$ ) furnishes tumor cells with the means of adapting to stress parameters like tumor hypoxia and promotes critical steps in tumor progression and aggressiveness. We investigated the role of hif- $1 \alpha$ expression in patients with node-positive breast cancer.
\end{abstract}

Methods: Tumor samples from 77 patients were available for immunohistochemistry. The impact of hif- $1 \alpha$ immunoreactivity on survival endpoints was determined by univariate and multivariate analyses, and correlations to clinicopathological characteristics were determined by cross-tabulations.

Results: hif- $1 \alpha$ was expressed in $56 \%(n=43 / 77)$ of the patients. Its expression correlated with progesterone receptor negativity $(P=0.002)$. The Kaplan-Meier curves revealed significantly shorter distant metastasis-free survival (DMFS) $(P=0.04$, log-rank) and disease-free survival (DFS) $(P=0.04$, log-rank) in patients with increased hif- $1 \alpha$ expression. The difference in overall survival (OS) did not attain statistical significance (5-year OS, 66\% without hif- $1 \alpha$ expression and $55 \%$ with hif- $1 \alpha$ expression; $P=0.21$ ). The multivariate analysis failed to reveal an independent prognostic value for hif- $1 \alpha$ expression in the whole patient group. The only significant parameter for all endpoints was the $\mathrm{T}$ stage (T3/T4 versus $\mathrm{T} 1 / \mathrm{T} 2$ : DMFS, relative risk $=3.16, P=0.01$; DFS, relative risk $=$ 2.57, $P=0.03$; OS, relative risk $=3.03, P=0.03$ ). Restricting the univariate and multivariate analyses to T1/T2 tumors, hif- $1 \alpha$ expression was a significant parameter for DFS and DMFS.

Conclusions: hif- $1 \alpha$ is expressed in the majority of patients with node-positive breast cancer. It can serve as a prognostic marker for an unfavorable outcome in those with T1/T2 tumors and positive axillary lymph nodes.

Keywords: breast cancer, hypoxia-inducible factor 1 alpha, prognostic marker, tumor hypoxia

\section{Introduction}

Intratumoral hypoxia has been shown to be a prognostic parameter in diverse studies [1]. Electrode measurements of oxygen tension have thus far served as the gold standard for its determination. The disadvantage of this method is its inability to discriminate between different cell types and areas of different cell viability [2].

Hypoxia-inducible factor 1 is a heterodimeric DNA-binding complex, of which the $\beta$ subunit is responsible for its translocation into the nucleus and the $\alpha$ subunit for its oxygen sensitivity. Under normoxic conditions the hypoxia-inducible factor 1 alpha (hif-1 $\alpha$ ) protein is degraded within minutes, whereas under hypoxic conditions it is stabilized and upregulated [3]. hif- $1 \alpha$ is a transcription factor for target genes, involved in cell adaptation to stress parameters such as hypoxia. These genes are involved mainly in the modulation of erythropoesis, angiogenesis and metabolism.

A spatial coexpression of hif- $1 \alpha$ and the nitroimidazole EF5, the levels of which are selectively lowered only in viable hypoxic cells, was recently reported [4]. Further- 
more, a correlation has been found to exist between hif- $1 \alpha$ immunoreactivity and tumor hypoxia as defined using the Eppendorf oxygen electrode [5]. Both findings indicate that hif- $1 \alpha$ might serve as a potential marker for intratumoral hypoxia.

In one study hif- $1 \alpha$ has been reported to be involved in breast carcinogenesis [6]. hif- $1 \alpha$ expression in normal breast tissue was compared with that in different pathological stages of breast cancer. hif- $1 \alpha$ was detected neither in normal tissue nor in hyperplastic ductal lesions, but it was expressed at progressively increasing levels in higher stage tumors. Since the overexpression of hif- $1 \alpha$ has been reported for 13 of 19 common tumor types [7], it may play an important role in tumorigenesis generally.

Data relating to the clinical impact of hif- $1 \alpha$ expression in breast cancer are scarce and controversial in nodepositive cases $[8,9]$. The aim of the present study was to investigate the consequence of its expression on the clinical outcome of patients with node-positive breast cancer, who carry a high risk of relapse.

In this series hif- $1 \alpha$ is expressed in the majority of patients with node-positive breast cancer. We can support the use of hif- $1 \alpha$ expression as a prognostic parameter in nodepositive patients, although its value was restricted to patients with $\mathrm{T} 1 / \mathrm{T} 2$ tumors.

\section{Materials and methods}

Patients with non-disseminated breast cancer and a high risk for relapse were eligible for this study. 'High risk' was defined by the presence of lymph node metastasis and extracapsular spreading of the tumor in one or more axillary lymph nodes. Between August 1988 and June 1998 this information was available in 81 patients with a median age of 57 years (mean age, 56 years; age range, 26-87 years) who met these criteria according to our database. Paraffin-embedded tissue samples from 77 patients were obtained.

The clinical characteristics of the patient cohort are summarized in Table 1. The ductal breast carcinomas were graded I, II and III based on the Scarff-Bloom and Richardson grading system modified by Elston and Ellis. All patients had segmental mastectomy with axillary lymph node dissection (level I, level II, or \pm level III) or modified radical mastectomy. The median number of lymph nodes examined was 15 (mean, 17; range, 6-37), of which a median number of five (mean, seven; range, 1-27) were positive. The total number of lymph nodes could not be precisely defined in seven patients owing to conglomeration. Since the pathological reports noted many lymph nodes to be metastatic, these patients were included in the subgroup with $>3$ positive
Systemic adjuvant treatment was administered to all but three patients, who refused it. The treatment consisted of tamoxifen $(n=59)$, toremifen $(n=3)$ or chemotherapy $(n=64)$. The chemotherapeutic regimens used were: adriamycin or epirubicin and cyclophosphamide in 13 cases; cyclophosphamide, methotrexate and 5-fluorouracil (5-FU) in 16 cases; and adriamycin or epirubicin and cyclophosphamide followed by cyclophosphamide, methotrexate and 5-FU in 28 cases. The following treatment combinations were given to single patients: cyclophosphamide, methotrexate, 5-FU, vincristine and prednisone; adriamycin or epirubicin and cyclophosphamide/ docetaxel or paclitaxel and cyclophosphamide; and docetaxel or paclitaxel and adriamycin or epirubicin/ cyclophosphamide, methotrexate and 5-FU. 5-FU, adriamycin or epirubicin and cyclophosphamide was given to four patients.

All patients underwent radiotherapy. In 46 of these patients radiotherapy was local only, whereas in the other 35 patients the ipsilateral subclavian region, the infraclavicular chest wall and level III of the axilla were also irradiated. A monocentric four-field technique was used to cover the locoregional target volume. The median total dose was 50.4 Gy for the lymphatics. Irradiation of the chest wall or breast was performed using single doses of 1.8 or $2 \mathrm{~Gy}$, which summed to a total dose of 48.6-64.8 Gy (median, 50.4 Gy).

The mean follow-up time was 36 months (range, 12-95 months).

\section{Immunohistochemistry}

After approval of the regional ethical committee, paraffinembedded tissues from 77 patients were collected and processed for immunohistochemistry. Sections $(3 \mu \mathrm{m}$ thick) were transferred to gelatinized microslides and were air-dried overnight at $37^{\circ} \mathrm{C}$. They were dewaxed in xylene (three changes), rehydrated in a graded series of decreasing ethanol concentration and then rinsed in Trisbuffered saline $(50 \mathrm{mM}$ Tris- $\mathrm{HCl}[\mathrm{pH}$ 7.4] containing $100 \mathrm{mM}$ sodium chloride).

Immunostaining for hif- $1 \alpha$ was performed according to the Catalyzed Signal Amplification System (Dako, Carpinteria, CA, USA), which utilizes a streptavidin-biotin-horseradish peroxidase complex. The slides were initially immersed in target retrieval solution (Dako) at $97^{\circ} \mathrm{C}$ for $15 \mathrm{~min}$ and were then treated in accordance with the manufacturer's instructions. They were exposed to a monoclonal antibody H1a67 (Novus Biologicals, Littleton, CO, USA) diluted 1:5000 for $30 \mathrm{~min}$ at ambient temperature. The biotinyl tyramide amplification reagent was diluted 1:10 in protein blocking solution (Dako). In the case of mouse anti-CD31, the antibody reaction is preceded by treatment with trypsin $\left(0.2 \mathrm{mg} / \mathrm{ml}\right.$ in $\mathrm{TBS} / \mathrm{CaCl}_{2}$ buffer; Difco Laboratories, 
Detroit, MI, USA) for $10 \mathrm{~min}$ at $37^{\circ} \mathrm{C}$. After the blockage of nonspecific binding by immersion in TBS containing $1 \%$ casein (SIGMA 8654) for $10 \mathrm{~min}$, sections were incubated with the first antibody diluted in TBS: mouse antiCD31, 1:20 (JC/70A, M-0823; Dako, Glostrup, Denmark) (for details, see [10]).

The reaction product was visualized by exposing sections to 3,3-diaminobenzidine for $1 \mathrm{~min}$ at ambient temperature. Nuclei were lightly counterstained with hematoxylin. Sections were then mounted in Aquatex ${ }^{\circledR}$ (Merck, Darmstadt, Germany). Tissue samples incubated with nonimmune serum or with the antibody diluent (Dako) served as negative controls. Sections from a previous study on mesopharynx carcinoma [10] were employed as a positive control. The quality (number, intensity and pattern) of every staining procedure for hypoxia-inducible factor $1 \alpha$ has been comparatively evaluated using consecutive control sections.

Tumor-cell immunoreactivity was scored according to both the extent of nuclear staining (relative number of hif- $1 \alpha$ positive cells) and the intensity of the reaction: -, not detected; $(+),<1 \%$ positive cells;,$+ 1-10 \%$ weakly to moderately stained cells;,$++ 1-10 \%$ intensively stained cells or $10-50 \%$ weakly stained cells;,$+++ 10-50 \%$ positive cells with moderate to marked staining; ++++, $>50 \%$ positive cells.

For the statistical analysis, the six grades of staining were reduced to three grades: negative, $[0 /(+)] ; \mathrm{I}$, moderate $[+/++]$; and II, intense [+++/++++]. The assessment was performed in a blinded fashion by an experienced investigator (VD).

\section{Statistics}

The bivariate analysis involving hif- $1 \alpha$ expression and clinicopathological covariables was performed using chisquare tests, the level of significance being $5 \%$.

The following endpoints were examined for survival analyses: distant metastasis-free survival (DMFS), diseasefree survival (DFS) and overall survival (OS). Survival time was calculated from the time of surgery until death (for OS) or, if the patient was still alive, until the last follow-up visit (for DMFS and for DFS). Local, regional or distant tumor progression was taken into account as adverse events for DFS, whereas for DMFS only distant tumor progression was considered. Death from any cause was considered for OS. Local progression-free survival, DFS and OS curves were plotted according to the KaplanMeier method, the log-rank test being used to determine the significance of differences between these. Parameters with $P<0.1$ in the univariate analysis were included in the multivariate Cox regression analysis (enter limit, 0.1; remove limit, 0.05).
Figure 1

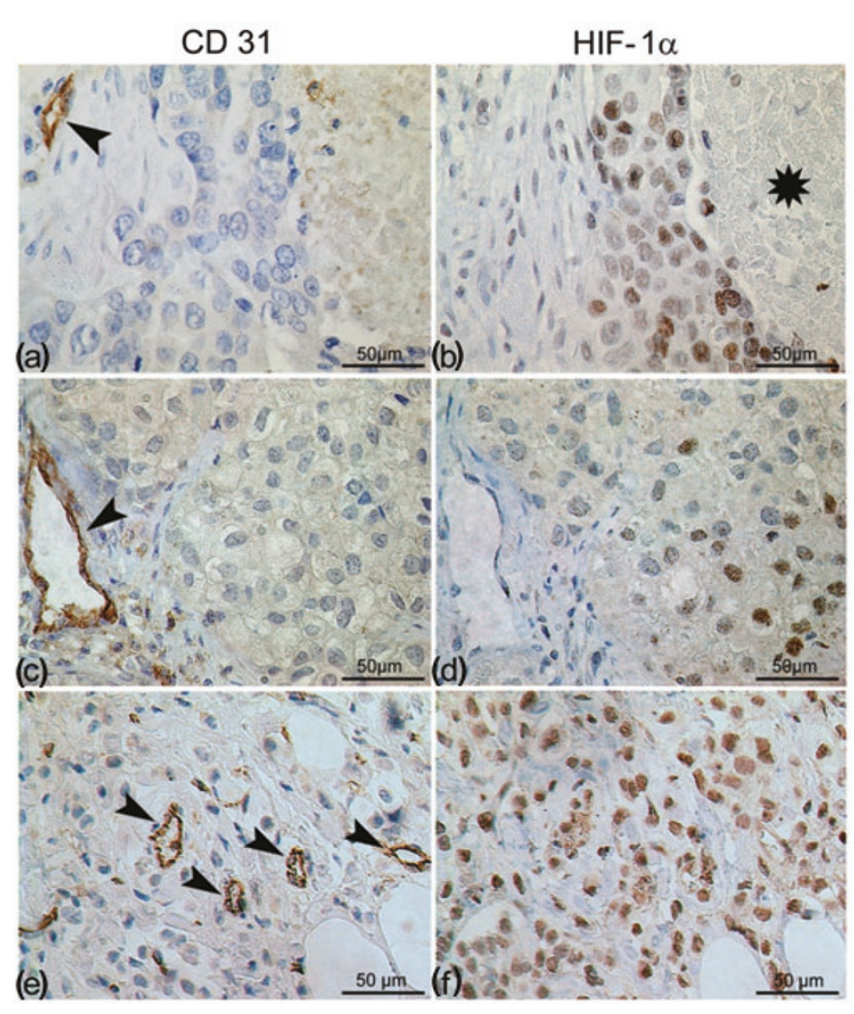

Immunohistochemical staining on consecutive sections for (a), (c) and (e) CD31 and (b), (d) and (f) hypoxia-inducible factor 1 alpha (hif-1 $\alpha$ ) in human breast cancer. Classical hif- $1 \alpha$ expression (b) at the border of a necrotic region or (c) and (d) at a distance of 100-150 $\mu \mathrm{m}$ from blood vessels. (e) and (f) Occasional diffuse hif- $1 \alpha$ staining throughout the entire tumor unpersuaded by the presence of capillary vessels. Asterisk denotes necrotic area. Arrowheads point to capillaries.

\section{Results}

\section{All patients}

Thirty-four patients (44\%) qualified for the 'negative' hif- $1 \alpha$ expression group, 25 patients (33\%) for the 'moderate' hif- $1 \alpha$ expression group and 18 patients $(23 \%)$ qualified for the 'intense' hif- $1 \alpha$ expression group. Three patterns of nuclear staining were encountered: focal expression, at the rim of a necrotic area (Fig. 1a,b) or with the most intense reaction occurring distal to the closest vessels (Fig. 1c,d); or diffuse expression, which was independent of vessel proximity (Fig. 1e,f). In most patients, there was no exclusivity for one or the other staining pattern.

The cross-tabulations for patient-related, tumor-related and therapy-related parameters are summarized in Table 1. There was no correlation with well-known prognostic parameters, such as the T stage, the grade or the number of positive lymph nodes. A statistically significant association existed only between hif- $1 \alpha$ expression and progesterone receptor expression $(P=0.006)$. 
Table 1

\begin{tabular}{|c|c|c|c|c|c|}
\hline \multirow[b]{2}{*}{ Parameter } & \multirow[b]{2}{*}{$n(\%)$} & \multicolumn{3}{|c|}{ hif- $1 \alpha$} & \multirow[b]{2}{*}{$P$} \\
\hline & & Negative & Weak & Strong & \\
\hline Total & $77(100)$ & $34(44)$ & 25 (33) & $18(23)$ & \\
\hline \multicolumn{6}{|l|}{ Age } \\
\hline$<50$ years & $23(30)$ & $8(35)$ & $10(43)$ & $5(22)$ & 0.38 \\
\hline$>50$ years & $54(70)$ & $26(48)$ & $15(28)$ & $13(24)$ & \\
\hline \multicolumn{6}{|l|}{ T stage } \\
\hline $\mathrm{T} 1 / \mathrm{T} 2$ & $55(71)$ & $26(48)$ & $16(30)$ & $13(22)$ & 0.57 \\
\hline $\mathrm{T} 3 / \mathrm{T} 4$ & $22(29)$ & $8(36)$ & $9(41)$ & $5(23)$ & \\
\hline \multicolumn{6}{|c|}{ Differentiation/grade } \\
\hline Moderate/G2 & $43(56)$ & $20(46)$ & $12(28)$ & $11(26)$ & 0.68 \\
\hline Poor/G3 & $32(42)$ & $12(37)$ & $13(41)$ & $7(22)$ & \\
\hline \multicolumn{6}{|c|}{ Number of lymph nodes } \\
\hline $1-3$ & $27(35)$ & $14(52)$ & $8(30)$ & $5(18)$ & 0.58 \\
\hline$\geq 4$ & $50(65)$ & $20(40)$ & 17 (34) & $13(26)$ & \\
\hline \multicolumn{6}{|l|}{ Estrogen receptor } \\
\hline Positive & $51(66)$ & $26(51)$ & $14(27)$ & $11(22)$ & 0.23 \\
\hline Negative & $26(34)$ & $8(31)$ & $11(42)$ & $7(27)$ & \\
\hline \multicolumn{6}{|c|}{ Progesterone receptor } \\
\hline Positive & $41(53)$ & $25(61)$ & $9(22)$ & $7(17)$ & 0.006 \\
\hline Negative & $36(47)$ & $9(25)$ & $16(44)$ & 11 (31) & \\
\hline \multicolumn{6}{|l|}{ Hormonotherapy } \\
\hline Yes & $62(81)$ & $27(43)$ & $19(31)$ & 16(26) & 0.56 \\
\hline No & 15 (19) & $7(47)$ & $6(40)$ & $2(13)$ & \\
\hline \multicolumn{6}{|l|}{ Chemotherapy } \\
\hline Yes & $64(83)$ & $25(39)$ & $23(36)$ & 16(25) & 0.13 \\
\hline No & $13(17)$ & $9(69)$ & $2(15)$ & $2(15)$ & \\
\hline
\end{tabular}

The actuarial 5-year DMFS, DFS and OS were 49\%, 50\% and $59 \%$, respectively. All deaths were judged to be related to disseminated breast cancer. In the univariate analysis, patients with higher hif- $1 \alpha$ scores had a poorer outcome. The relationship attained statistical significance for DMFS and DFS if 'hif- $1 \alpha$-positive' tumors were matched against the 'negative' group $(P=0.04$ in each case; Table 2). The Kaplan-Meier curves for DFS and for hif- $1 \alpha$ expression are shown in Fig. 2 for all patients.

The hif- $1 \alpha$ expression and parameters with $P<0.1$ in the univariate analysis were included in a Cox regression model. The multivariate analysis revealed the 'number of
( $P=0.02$ each), whereas the 'age', the 'estrogen receptor status' and the 'hif- $1 \alpha$ expression' failed to obtain statistical significance (Table 3). The only factor that was found to be important for all three endpoints was the 'advanced T stage' (DMFS, relative risk $=3.16, P=0.01$; DFS, relative risk $=2.57, P=0.03$; OS, relative risk $=$ 3.03, $P=0.03$ ).

\section{Patients with T1/T2 tumors}

Since an advanced tumor stage was found to be the most important prognostic factor, we stratified the analyses according to the $T$ stage in order to ascertain whether hif- $1 \alpha$ had a prognostic impact in a subset of patients. No significant impact was found for hif- $1 \alpha$ expression in 
Table 2

\begin{tabular}{|c|c|c|c|c|c|c|}
\hline Parameter & $\begin{array}{c}\text { Distant metastasis-free } \\
\text { survival }\end{array}$ & $P$ & $\begin{array}{l}\text { Disease-free } \\
\text { survival }\end{array}$ & $P$ & $\begin{array}{l}\text { Overall } \\
\text { survival }\end{array}$ & $P$ \\
\hline Actuarial 5-year data (standard deviation) & $49( \pm 9)$ & & $50( \pm 10)$ & & $59( \pm 9)$ & \\
\hline \multicolumn{7}{|l|}{ Age } \\
\hline$<50$ years & $37( \pm 15)$ & & $43( \pm 14)$ & & $38( \pm 16)$ & \\
\hline$>50$ years & $52( \pm 12)$ & 0.09 & $51( \pm 12)$ & 0.09 & $69( \pm 10)$ & 0.06 \\
\hline \multicolumn{7}{|l|}{ T stage } \\
\hline $\mathrm{T} 1 / \mathrm{T} 2$ & $66( \pm 9)$ & & $68( \pm 8)$ & & $75( \pm 9)$ & \\
\hline T3/T4 & $16( \pm 13)$ & 0.001 & $16( \pm 13)$ & 0.003 & $26( \pm 15)$ & 0.01 \\
\hline \multicolumn{7}{|l|}{ Differentiation/grade } \\
\hline Moderate/G2 & $54( \pm 12)$ & & $58( \pm 11)$ & & $49( \pm 15)$ & \\
\hline Poor/G3 & $42 \pm 15)$ & 0.40 & $42( \pm 15)$ & 0.52 & $67( \pm 12)$ & 0.84 \\
\hline \multicolumn{7}{|l|}{ Number of positive lymph nodes } \\
\hline $1-3$ & $64( \pm 20)$ & & $60( \pm 21)$ & & $80( \pm 15)$ & \\
\hline$\geq 4$ & $41( \pm 10)$ & 0.005 & $43( \pm 10)$ & 0.004 & $50( \pm 11)$ & 0.03 \\
\hline \multicolumn{7}{|l|}{ Estrogen receptor } \\
\hline Positive & $57( \pm 14)$ & & $58( \pm 14)$ & & $63( \pm 13)$ & \\
\hline Negative & $37( \pm 12)$ & 0.04 & $36( \pm 12)$ & 0.03 & $52( \pm 13)$ & 0.14 \\
\hline \multicolumn{7}{|l|}{ Progesterone receptors } \\
\hline Positive & $47( \pm 20)$ & & $50( \pm 21)$ & & $56( \pm 16)$ & \\
\hline Negative & $46( \pm 10)$ & 0.22 & $46( \pm 11)$ & 0.21 & $60( \pm 12)$ & 0.83 \\
\hline \multicolumn{7}{|l|}{ hif- $1 \alpha$ expression } \\
\hline Intense & $38( \pm 15)$ & & $38( \pm 15)$ & & $53( \pm 17)$ & \\
\hline Moderate & $48( \pm 14)$ & & $50( \pm 13)$ & & $50( \pm 22)$ & \\
\hline No & $56( \pm 16)$ & 0.12 & $58( \pm 16)$ & 0.13 & $66( \pm 13)$ & 0.46 \\
\hline \multicolumn{7}{|l|}{ hif- $1 \alpha$ expression } \\
\hline Yes & $43( \pm 10)$ & & $44( \pm 10)$ & & $55( \pm 13)$ & \\
\hline No & $56( \pm 16)$ & 0.04 & $58( \pm 16)$ & 0.04 & $66( \pm 13)$ & 0.21 \\
\hline
\end{tabular}

hif- $1 \alpha$, hypoxia-inducible factor 1 alpha.

patients with T3/T4 tumors (for DFS, $P=0.66$; for DMFS, $P=0.38$; for OS, $P=0.16)$.

We then restricted the survival analysis to 55 patients with $\mathrm{T} 1 / \mathrm{T} 2$ tumors. The univariate analysis for DFS revealed the 'number of positive nodes' $(P=0.002)$ and the 'hif- $1 \alpha$ expression' ('negative' versus 'moderate' versus 'intense', $P=0.028$ ) as significant (Fig. 3). 'Hormonal treatment' was of borderline significance $(P=0.09)$. For DMFS, the 'number of positive nodes' $(P=0.002)$ and the 'hif- $1 \alpha$ expression' ('negative' versus 'moderate' versus 'intense', $P=0.016)$ were significant. The 'number of positive nodes' was the only significant parameter for OS $(P=0.02)$.
A multivariate analysis including the aforementioned parameters was performed for DMFS and DFS. Beside the 'number of positive nodes', the 'hif- $1 \alpha$ expression' was significant for both DMFS (relative risk $=7.12, P=0.01$ ) and DFS (relative risk $=7.04, P=0.01$ ), whereas 'hormonal treatment' did not attain significance in patients with T1/T2 tumors.

\section{Discussion}

Findings over the past few years indicate that genetically modified cells [11] with an enhanced metastatic potential [12] and those with diminished apoptosis [13] selectively survive under hypoxic conditions, and that hypoxia may be 
Figure 2

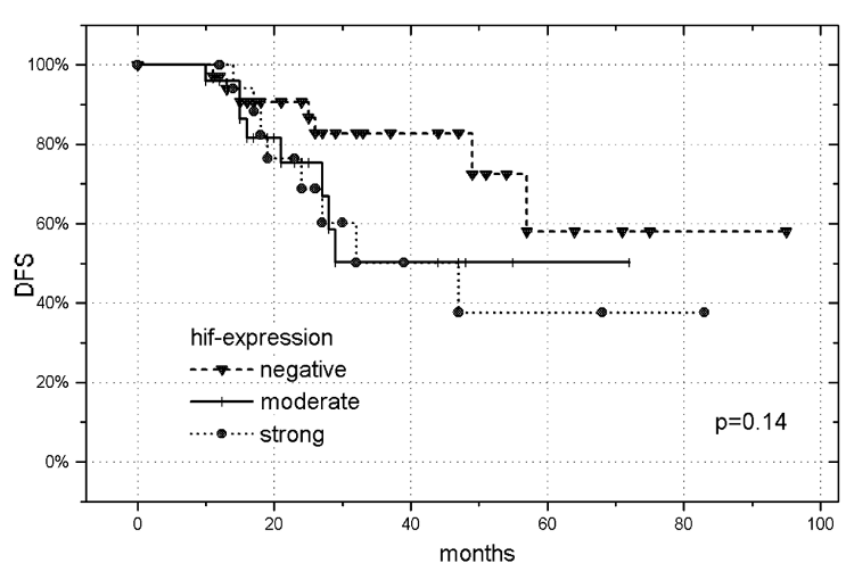

Disease-free survival (DFS) of 77 patients with high-risk breast cancer, as a function of 'negative' versus 'moderate' versus 'intense' hypoxiainducible factor (hif) 1 alpha expression.
Figure 3

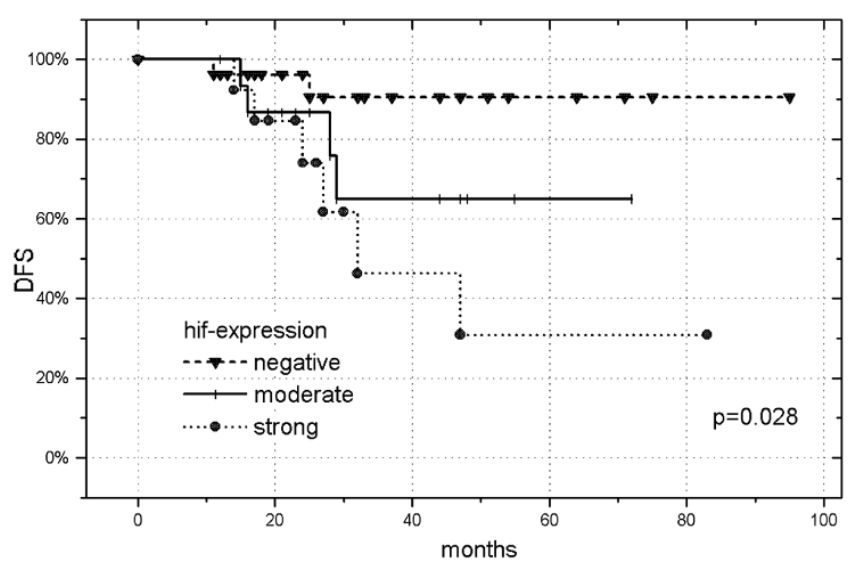

Disease-free survival (DFS) of 55 patients with $\mathrm{T} 1 / \mathrm{T} 2$ breast cancer as a function of 'negative' versus 'moderate' versus 'intense' hypoxiainducible factor (hif) 1 alpha expression.

Table 3

Multivariate survival analyses (Cox regression model) in node-positive breast cancer $(n=77)$

\begin{tabular}{|c|c|c|c|c|c|c|}
\hline & \multicolumn{2}{|c|}{ Distant metastasis-free survival } & \multicolumn{2}{|r|}{ Disease-free survival } & \multicolumn{2}{|r|}{ Overall survival } \\
\hline & $P$ & $\begin{array}{c}\text { Relative risk } \\
\text { (95\% confidence interval) }\end{array}$ & $P$ & $\begin{array}{c}\text { Relative risk } \\
\text { (95\% confidence interval) }\end{array}$ & $P$ & $\begin{array}{c}\text { Relative risk } \\
\text { (95\% confidence interval) }\end{array}$ \\
\hline \multicolumn{7}{|l|}{ Age } \\
\hline$>50$ years versus $<50$ years & 0.14 & $0.50(0.20-1.26)$ & 0.20 & $0.56(0.23-1.36)$ & 0.13 & $0.43(0.15-1.29)$ \\
\hline \multicolumn{7}{|l|}{ T stage } \\
\hline $\mathrm{T} 3 / \mathrm{T} 4$ versus $\mathrm{T} 1 / \mathrm{T} 2$ & 0.01 & $3.16(1.32-7.58)$ & 0.03 & $2.57(1.08-6.11)$ & 0.03 & $3.03(1.08-8.51)$ \\
\hline \multicolumn{7}{|l|}{ Estrogen receptor } \\
\hline Positive versus negative & 0.32 & $0.64(0.26-1.56)$ & 0.18 & $0.54(0.22-1.33)$ & - & \\
\hline \multicolumn{7}{|l|}{ Number of positive lymph nodes } \\
\hline $4+$ versus $1-3$ & 0.02 & $4.06(1.17-14.01)$ & 0.02 & $4.42(1.28-15.32)$ & 0.16 & $3.00(0.64-13.97)$ \\
\hline \multicolumn{7}{|l|}{ hif- $1 \alpha$ expression } \\
\hline Yes versus no & 0.18 & $1.94(0.73-5.17)$ & 0.30 & $1.68(0.62-4.47)$ & 0.09 & $2.66(0.83-8.51)$ \\
\hline
\end{tabular}

hif- $1 \alpha$, hypoxia-inducible factor 1 alpha.

a major parameter governing this selection. Once equipped with the possibilities for survival under adverse microenvironmental conditions, tumor cells are probably also more resistant to cytotoxic therapies. This is especially true for radiotherapy, but it might also be important for pharmacotherapy with drugs such as cyclophosphamide, adriamycin or 5-FU [14], which are often used in the adjuvant treatment of breast cancer.

Malignant breast tumors are known to contain heterogeneously distributed hypoxic areas with a median oxygen tension of $23-28 \mathrm{mmHg}$, which is well below that involving cervical cancer have oxygen tension measurements been compared with hif- $1 \alpha$ staining; a significant correlation was found to exist [5]. As previously described $[4,7]$, staining for hif- $1 \alpha$ reflects two different expression patterns. The first depends on the distance from blood vessels, and on the proximity of necrotic regions, which may accord with a decrease in oxygen concentration. The other expression pattern is manifested as a diffuse immunoreactivity throughout the entire tumor, indicating that hif- $1 \alpha$ expression can be influenced by factors other than hypoxia. Indeed, growth factors and their receptors, as well as the activation of other oncogenic signal transduction pathways, may play a crucial role in the 
upregulation of hif- $1 \alpha$ expression irrespective of tumor hypoxia [3].

An increasing body of evidence indicates that hif- $1 \alpha$ expression is inversely correlated with tumor control and/or patient survival. This has been demonstrated to date for oligodendroglioma [18] and for a broad range of carcinomas at different sites, such as the endometrium [19], the uterine cervix $[20,21]$, the ovary [22], the esophagus [23], the lung [24], the head and neck [10,25] and the breast $[8,9]$. In contrast, other studies have revealed either no correlation between hif- $1 \alpha$ expression and outcome $[5,26]$ or an improved survival rate $[27,28]$. These conflicting results may be explained either by the low number of patients, and/or the existence of factors that do not attain statistical significance, or by the specific sensitivity of tumor cells towards a certain therapy. Our data point to another possibility; namely, patient selection. There is no doubt that the risk of subclinical distant metastases at the time of diagnosis parallels the $T$ stage and the $\mathrm{N}$ stage. At a certain point of tumor progression, a biological marker will probably lose its prognostic value relative to the prognosticators for a worse outcome (namely, increased tumor size and lymph node metastases), even if the marker was instrumental in tumor development and the aggressiveness of the disease.

Only two reports deal with the prognostic impact of hif- $1 \alpha$ expression in breast cancer. Bos and colleagues [9] reported on 81 node-negative patients and 69 nodepositive patients treated between 1985 and 1993. High levels of hif- $1 \alpha$ had a profound impact on OS and DFS in the subgroup of patients with node-negative tumors, but had no influence on those with node-positive tumors [9]. In this series 139 out of 150 patients had T1 or T2 tumors, locally advanced tumours having been excluded. Schindl and colleagues' study [8] involved only nodepositive patients, almost all of these having T1 or T2 tumors (192 of the 206 patients), and hif- $1 \alpha$ expression was highly significant.

The findings of Schindl and colleagues regarding $\mathrm{T} 1$ and T2 tumours are in agreement with our results. On the contrary, Bos and colleagues did not make the same observation. The discrepancy might be explained by the circumstance that only patients with node-positive disease underwent systemic therapy in Schindl and colleagues' series, which might have influenced the prognostic value of hif- $1 \alpha$ expression. No correlation was found to exist between hif- $1 \alpha$ expression and the most important factors for outcome (namely, the $\mathrm{T}$ stage $[8,9]$ and the $\mathrm{N}$ stage [9]), which supports our findings. More T3 and T4 tumors were included in our study than in the previous studies, which is an important circumstance since hif- $1 \alpha$ expression differed significantly in the univariate analysis but not in the multivariate analysis for DFS in the presence of these T3/T4 tumors. After exclusion of T3/T4 tumors, hif- $1 \alpha$ expression was a significant and independent factor for DFS. It would appear that, in advanced disease, the upregulation of hif- $1 \alpha$ as a prognostic marker is repressed by other adaptive mechanisms.

In all other cases, the inhibition of hif- $1 \alpha$ pathways represents a promising approach to the counteraction of tumor progression. Concomitant treatment with hif- $1 \alpha$ antisense agents and cytotoxic drugs, such as cisplatin, etoposide and vincristine, has been shown to have a synergistic effect in vitro [29]. More data are required, however, to assess the probable consequences in a clinical setting.

\section{Conclusions}

In the present study, hif- $1 \alpha$ was expressed in the majority of node-positive breast cancer patients. The presence of this protein is predictive of a poor outcome, although its impact is less evident than an advanced $T$ stage or the number of positive lymph nodes. In addition to the number of positive lymph nodes, however, hif- $1 \alpha$ expression status offers the possibility of defining disease-free survival more precisely than other patient-related or tumor-related parameters in $\mathrm{T} 1 / \mathrm{T} 2$ tumors.

On the basis of our findings, it would appear that novel biological markers can lose their prognostic value in locally advanced disease stages. Nevertheless, they might furnish additional information to the TNM staging system in subgroups of patients.

\section{Competing interests}

None declared.

\section{Acknowledgements}

The authors would like to thank B DeBreuyn and R Buergy for their excellent technical assistance. This work was supported by the 'Bernese Radium Foundation' and Bernese Cancer League.

\section{References}

1. Stone HB, Brown JM, Phillips TL, Sutherland RM: Oxygen in human tumors: correlations between methods of measurement and response to therapy. Summary of a workshop held November 19-20, 1992, at the National Cancer Institute, Bethesda, Maryland. Radiat Res 1993, 136:422-434.

2. Raleigh JA, Dewhirst MW, Thrall DE: Measuring tumor hypoxia. Semin Radiat Oncol 1996, 6:37-45.

3. Semenza GL: Signal transduction to hypoxia-inducible factor 1. Biochem Pharmacol 2002, 64:993-998.

4. Vukovic V, Haugland HK, Nicklee T, Morrison AJ, Hedley DW: Hypoxia-inducible factor-1alpha is an intrinsic marker for hypoxia in cervical cancer xenografts. Cancer Res 2001, 61: 7394-7398.

5. Haugland HK, Vukovic V, Pintilie M, Fyles AW, Milosevic M, Hill $\mathrm{RP}$, Hedley DW: Expression of hypoxia-inducible factor-1 $\alpha$ in cervical carcinomas: correlation with tumor oxygenation. Int $J$ Radiat Oncol Biol Phys 2002, 53:854-861.

6. Bos R, Zhong H, Hanrahan CF, Mommers EC, Semenza GL, Pinedo HM, Abeloff MD, Simons JW, van Diest PJ, van der Wall E: Levels of hypoxia-inducible factor-1 alpha during breast carcinogenesis. J Natl Cancer Inst 2001, 93:309-314. 
7. Zhong H, De Marzo AM, Laughner E, Lim M, Hilton DA, Zagzag D, Buechler P, Isaacs WB, Semenza GL, Simons JW: Overexpression of hypoxia-inducible factor 1alpha in common human cancers and their metastases. Cancer Res 1999, 59:58305835 .

8. Schind $M$, Schoppmann SF, Samonigg $H$, Hausmaninger $H$ Kwasny W, Gnant M, Jakesz R, Kubista E, Birner P, Oberhuber G, Austrian Breast and Colorectal Cancer Study Group: Overexpression of hypoxia-inducible factor $1 \alpha$ is associated with an unfavourable prognosis in lymph node-positive breast cancer. Clin Cancer Res 2002, 8:1831-1837.

9. Bos R, van der Groep P, Greijer AE, Shvarts A, Meijer S, Pinedo $H M$, Semenza GL, van Diest PJ, van der Wall E: Levels of hypoxia-inducible factor-1alpha independently predict prognosis in patients with lymph node negative breast carcinoma. Cancer 2003, 97:1573-1581.

10. Aebersold DM, Burri P, Beer KT, Laissue J, Djonov V, Greiner RH, Semenza GL: Expression of hypoxia-inducible factor-1alpha: a novel predictive and prognostic parameter in the radiotherapy of oropharyngeal cancer. Cancer Res 2001, 61:2911-2916.

11. Reynolds TY, Rockwell S, Glazer PM: Genetic instability induced by the tumor microenvironment. Cancer Res 1996, 56:5754-5757.

12. Rofstad EK: Microenvironment-induced cancer metastasis. Int $J$ Radiat Biol 2000, 76:589-605.

13. Graeber TG, Osmanian C, Jacks T, Housman DE, Koch CJ, Lowe SW, Giaccia AJ: Hypoxia-mediated selection of cells with diminished apoptotic potential in solid tumours. Nature 1996, 379:88-91.

14. Teicher BA, Holden SA, al-Achi A, Herman TS: Classification of antineoplastic treatments by their differential toxicity toward putative oxygenated and hypoxic tumor subpopulations in vivo in the FSallC murine fibrosarcoma. Cancer Res 1990, 50: 3339-3344.

15. Vaupel P, Schlenger K, Knoop C, Höckel M: Oxygenation of human tumors: evaluation of tissue oxygen distribution in breast cancers by computerized $\mathrm{pO}_{2}$ tension measurements. Cancer Res 1991, 51:3316-3322.

16. Falk SJ, Ward R, Bleehan NM: The influence of carbogen breathing on tumour tissue oxygenation in man evaluated by computerised $\mathrm{pO}_{2}$ histography. Br J Cancer 1992, 66:919-924.

17. Runkel S, Wischnik A, Teubner J, Kaven E, Gaa J, Melchert F: Oxygenation of mammary tumors as evaluated by ultrasoundguided computerized-pO $\mathrm{O}_{2}$-histography. Adv Exp Med Biol 1994, 345:451-458.

18. Birner P, Gatterbauer B, Oberhuber G, Schindl M, Rossler K, Prodinger A, Budka $\mathrm{H}$, Hainfellner JA: Expression of hypoxiainducible factor $1 \alpha$ in oligodendrogliomas: its impact on prognosis and on neoangiogenesis. Cancer 2001, 92:165-171.

19. Sivridis E, Giatromanolaki A, Gatter KC, Harris AL, Koukourakis MI: Tumor and Angiogenesis Research Group. Association of hypoxia-inducible factors 1alpha and 2alpha with activated angiogenic pathways and prognosis in patients with endometrial carcinoma. Cancer 2002, 95:1055-1063.

20. Birner $P$, Schindl M, Obermair A, Plank C, Breitenecker G, Oberhuber $\mathrm{G}$ : Overexpression of hypoxia-inducible factor 1 alpha is a marker for an unfavorable prognosis in early-stage invasive cervical cancer. Cancer Res 2000, 60:4693-4696.

21. Burri P, Djonov V, Aebersold DM, Lindel K, Studer U, Altermatt HJ, Mazzucchelli L, Greiner RH, Gruber G: Significant correlation of hypoxia-inducible factor-1alpha with treatment outcome in cervical cancer treated with radical radiotherapy. Int J Radiat Oncol Biol Phys 2003, 56:494-501.

22. Birner $P$, Schindl M, Obermair A, Breitenecker G, Oberhuber G: Expression of hypoxia-inducible factor $1 \alpha$ in epithelial ovarian tumors: its impact on prognosis and on response to chemotherapy. Clin Cancer Res 2001, 7:1661-1668.

23. Koukourakis Ml, Giatromanolaki A, Skarlatos J, Corti L, Blandamura S, Piazza M, Gatter KC, Harris AL: Hypoxia inducible factor (HIF-1 $\alpha$ and HIF-2 $\alpha$ ) expression in early esophageal cancer and response to photodynamic therapy and radiotherapy. Cancer Res 2001, 61:1830-1832.

24. Giatromanolaki A, Koukourakis MI, Sivridis E, Turley H, Talks K, Pezzella F, Gatter KC, Harris AL: Relation of hypoxia inducible factor 1 alpha and 2 alpha in operable non-small cell lung cancer to angiogenic/molecular profile of tumours and sur-
25. Koukourakis MI, Giatromanolaki A, Sivridis E, Simopoulos C Turley H, Talks K, Gatter KC, Harris AL: Hypoxia-inducible factor (HIF1A and HIF2A), angiogenesis, and chemoradiotherapy outcome of squamous cell head-and-neck cancer. Int J Radiat Oncol Biol Phys 2002, 53:1192-1202.

26. Nakayama K, Kanzaki A, Hata K, Katabuchi H, Okamura H, Miyazaki K, Fukumoto $M$, Takebayashi $Y$ : Hypoxia-inducible factor 1 alpha (HIF-1 alpha) gene expression in human ovarian carcinoma. Cancer Lett 2002, 176:215-223.

27. Volm M, Koomagi R: Hypoxia-inducible factor (HIF-1) and its relationship to apoptosis and proliferation in lung cancer. Anticancer Res 2000, 20:1527-1533.

28. Beasley NJ, Leek R, Alam M, Turley H, Cox GJ, Gatter K, Millard P, Fuggle S, Harris AL: Hypoxia-inducible factors HIF-1alpha and HIF-2alpha in head and neck cancer: relationship to tumor biology and treatment outcome in surgically resected patients. Cancer Res 2002, 62:2493-2497.

29. Dai S, Huang ML, Hsu CY, Chao KS: Inhibition of hypoxia inducible factor 1 alpha causes oxygen-independent cytotoxicity and induces p53 independent apoptosis in glioblastoma cells. Int J Radiat Oncol Biol Phys 2003, 55:1027-1036.

\section{Correspondence}

Valentin Djonov, MD, Buehlstrasse 26, Institute of Anatomy, University of Bern, CH-3012 Bern, Switzerland. Tel: +41 31 6314641; fax: +41

31 6313410; e-mail: djonov@ana.unibe.ch 